\title{
THE SCIENTIFIC BASIS OF INTENSIFICATION OF CARBON WIRE DRAWING SCHEDULES
}

\author{
${ }^{1}$ V.A. KHARITONOV, ${ }^{2}$ M. Yu. USANOV, ${ }^{1}$ L.V. NOSOV, ${ }^{1}$ D.V. GRACHEV, ${ }^{1}$ A.E. KOZHEMYAKINA \\ ${ }^{1}$ Nosov Magnitogorsk State Technical University, Magnitogorsk, Russia, \\ hva-46@yandex.ru, nosov.leopold@yandex.ru,.omp d.grachev@mail.ru, kozhemiakina.a@yandex.ru \\ ${ }^{2}$ Nosov Magnitogorsk State Technical University, branch in Beloretsk, Beloretsk, Russia, \\ barracudam@mail.ru
}

\section{https://doi.org/10.37904/metal.2021.4105}

\begin{abstract}
A wire manufacturing process includes wire rod structure and surface preparation (heat treatment), coating, shaping and other operations with finished wire. A key operation influencing the shape and properties is drawing using monolithic and roller dies of various structures.

Drawing shows a diagram of opposite principal stresses and a symmetric diagram of principal strains characterized by high efficiency of the deformation and lower energy consumption. Tensile stress $\sigma_{1}$ contributes to embrittlement during drawing, and maximum allowed value $\sigma_{1} \leq \sigma_{B}$ limits the strain rate in a pass.

Forming during drawing in monolithic dies is determined by a die reduction angle, reduction per die, friction factor and strain rate. When assessing force factors, the said factors include drawing force (stress) and ultimate tensile strength of the material under study.

The existing procedures are used to calculate limit single and aggregate reduction per die, die angle, force parameters and stability of the process. However, they do not factor into physical and mechanical properties of wire, its stress state in and out of a deformation zone.

Using hardness coefficient distribution fields and the Lode-Nadai coefficient in a conical deformation zone and hydrostatic stress distribution fields, we developed a stress state determination procedure and a new calculation method and algorithm of drawing sequences. Curves of hydrostatic stress on the wire axis and drawing force are built for various die reduction angles and reductions for carbon steels. This procedure may be applied both for designing new and analyzing existing drawing sequences used to produce wire of the set quality at minimum manufacturing costs.
\end{abstract}

Keywords: Wire, drawing, hydrostatic stress, drawing sequences, drawing force

\section{INTRODUCTION}

Drawing in monolithic dies is a main method of producing steel wire of various applications and in a broad range of sizes and properties. Drawing has a long history of development and many advantages over other deformation processes: high performance, producing round and shaped sections with high accuracy of geometrical sizes and surface quality, ensuring a required level of mechanical properties of finished wire, low metal waste (metal saving), coverage of theoretical studies, and a relatively simple and mature process. To carry out the process, there are various industry-standard facilities, which are continuously improved to intensify the process, increase the production output, combine bar surface preparation and drawing operations, increase the quality of finished wire, save energy, ensure ecological performance, etc. A range of the products manufactured by drawing is continuously expanded [1-4]. 
In addition to advantages, drawing has significant disadvantages: an unfavorable schedule of the stress and strain state in the deformation zone determined by tension stresses, additional shearing of surface layers in relation to central ones, which is a reason for their higher strengthening, and high contact friction on the boundary of steel and a die, entailing heating and strain aging of steel. Therefore, improvement of a drawing process mainly consists of development and application of better drawing oils and a method of delivering them to the deformation zone, improvement of the material and design of drawing tools, increase in efficiency of cooling wire and dies. Much attention should be devoted to the preparation of steel surface for drawing.

Other disadvantages of drawing may include a monotonous deformation process, non-homogeneous deformation due to partial working of the section, and a considerable dependence on a scale factor.

The results of the effect of all the above factors are reduced deformability of metal and lower ductility reserve.

Loss of steel ductility during drawing limits maximum permissible total reduction, achievement of a high level of strength and commercial-scale implementation of a high-strength state. Besides, all the parameters, both strength and ductility characteristics, tend to decrease as a result of a scale factor, when increasing a diameter of manufactured wire. Changes in mechanical properties of cold-drawn wire during drawing are of the greatest importance, as they contribute to achievement of a set level of strength and ductile properties of finished wire. Besides, ductility determines potential of downstream deformation during both drawing and subsequent processing of wire into products [5].

\section{RESEARCH METHOD}

Now, a main objective is to improve a process of drawing round wire, especially of large diameters, in monolithic dies. To achieve it, we assess a stress and strain state for a particular case or a drawing sequence. However, we should study a combined effect of a die reduction angle, reduction per die and friction factor in a particular deformation zone on the stress and strain state, and then design resource-saving drawing sequences. Thus, we need a procedure based on a system approach to the assessment of the stress and strain state and drawing force at various die angles, reductions and friction, factoring into physical and mechanical properties of wire.

Using simulation, we developed a procedure to assess the stress and strain state of wire, when drawing it in a tool with a conical deformation zone. Thus, applying a subroutine for Deform-3d, we got fields of distribution of rigidity factors for the Smirnov-Alyaev diagram and the Lode-Nadai coefficient, when drawing rods from steel grade 80 in monolithic dies. Using these values and assessing hydrostatic stress in the deformation zone, we developed a procedure for the assessment of the stress and strain state.

\section{SIMULATION RESULTS AND DISCUSSION}

Regarding length of a conical deformation zone, we got curves of rigidity factors on the wire axis and delta factors for various reduction values. Delta factors were calculated by the equation:

$$
\Delta=(\alpha / \varepsilon) \cdot(1+\sqrt{1-\varepsilon})^{2}
$$

where:

$$
\begin{aligned}
& \alpha \text { - semi-angle of a die reduction angle (radian) } \\
& \varepsilon \text { - reduction per die }
\end{aligned}
$$

We also analyzed changes in hydrostatic stress for steel grade 80 and developed a procedure to assess penetration depth of "sliding cones" in the deformation zone depending on delta factors for various die reduction angles (Figure 1). 


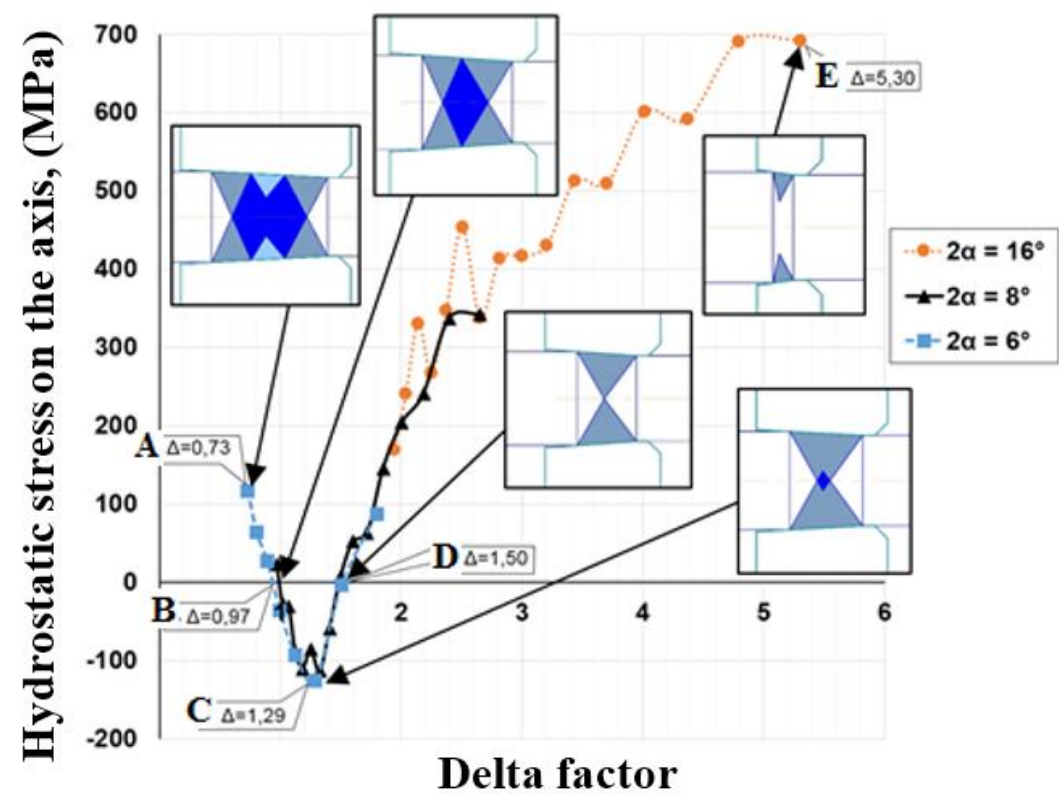

Figure 1 Curves of hydrostatic stress on the wire axis and the delta factor for die reduction angles $2 \alpha=6^{\circ}$, $8^{\circ}$ and $16^{\circ}$

The curve in Figure 1 shows that minimum delta factor is 0.73 (point A), and maximum one is 5.30 (point E). The curve crosses the $X$-axis twice, when delta factor is 0.97 (point $B$ ) and 1.50 (point D). Minimum hydrostatic stress corresponds to a delta factor of 1.29 (point C).

We studied the effect of drawing schedules on changes in the stress and strain state of wire in a conical deformation zone during drawing in monolithic dies and calculated drawing force and hydrostatic stress for a total range of practically applied die reduction angles $\left(2 \alpha=6-16^{\circ}\right)$ and reduction per die $(\varepsilon=8-41 \%)$ for wire from steel grade 80 with a diameter of $16.0 \mathrm{~mm}$ (Figure 2).

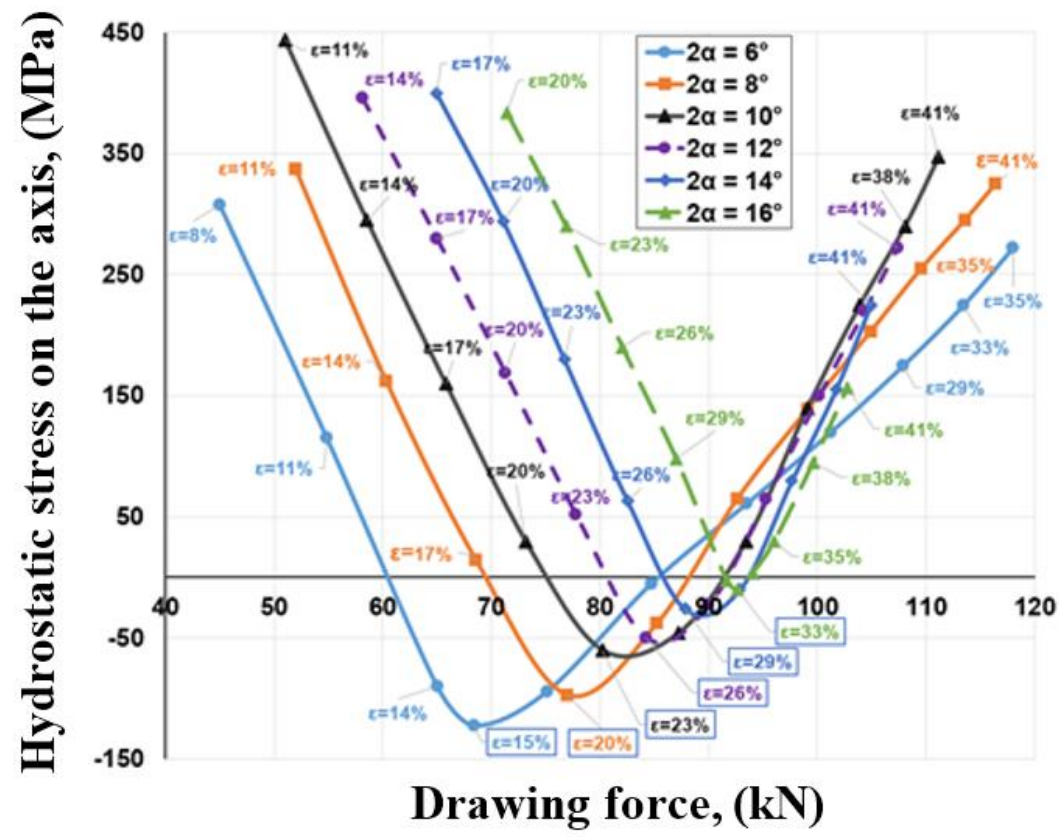

Figure 2 Curves of hydrostatic stress and drawing force for die reduction angles $2 \alpha=6-16^{\circ}$ and reduction per die $\varepsilon=8-41 \%$ 
We determined the curves of hydrostatic stress on the wire axis and drawing force for a "working" range of delta factor values from 1.20 to 2.0 and showed that minimum hydrostatic stress on the wire axis at die reduction angles of $6^{\circ}, 8^{\circ}$ and $10^{\circ}$ was at a delta factor of 1.29 , and for die reduction angles of $12^{\circ}, 14^{\circ}$ and $16^{\circ}$ is 1.40 . Every die reduction angle has an area of delta factor values and a reduction range ensuring maximum reduction at minimum drawing force. Recommended reduction values for the die reduction angles under study are given in Table 1.

Table 1 Recommended reduction values

\begin{tabular}{|c|c|c|c|c|c|c|}
\hline $\begin{array}{c}\text { Die } \\
\text { reduction } \\
\text { angle }\end{array}$ & $\begin{array}{c}\text { Delta } \\
\text { factor }\end{array}$ & $\begin{array}{c}\text { Reduction } \\
\text { range } \\
(\%)\end{array}$ & $\begin{array}{c}\text { Average } \\
\text { reduction } \\
(\%)\end{array}$ & $\begin{array}{c}\text { Drawing } \\
\text { range }\end{array}$ & $\begin{array}{c}\text { Average } \\
\text { drawing }\end{array}$ & $\begin{array}{c}\text { Drawing force at } \\
\text { minimum } \sigma_{\text {av }} \\
(\mathbf{k N})\end{array}$ \\
\hline $2 \alpha=6^{\circ}$ & $1.2-2.0$ & $10-16$ & 13.0 & $1.11-1.19$ & 1.15 & 68.4 \\
\hline $2 \alpha=8^{\circ}$ & $1.2-2.0$ & $13-21$ & 17.0 & $1.15-1.27$ & 1.20 & 77.0 \\
\hline $2 \alpha=10^{\circ}$ & $1.2-2.0$ & $16-25$ & 20.5 & $1.19-1.33$ & 1.26 & 80.2 \\
\hline $2 \alpha=12^{\circ}$ & $1.29-2.0$ & $19-28$ & 23.5 & $1.23-1.39$ & 1.31 & 84.2 \\
\hline $2 \alpha=14^{\circ}$ & $1.33-2.0$ & $22-31$ & 26.5 & $1.28-1.45$ & 1.36 & 87.8 \\
\hline $2 \alpha=16^{\circ}$ & $1.36-2.0$ & $25-34$ & 29.5 & $1.33-1.52$ & 1.42 & 92.6 \\
\hline
\end{tabular}

For example, let us calculate the drawing sequence from $16.00 \mathrm{~mm}$ in diameter to $8.00 \mathrm{~mm}$ according to the suggested procedure. Reduction angle in all dies $\alpha=6^{\circ}$.

According to Table 1 maximum reduction for such angle is $28 \%$, and average reduction is $23.5 \%$. Total drawing $\mu \Sigma=4$. Regarding reduction angle $\alpha=6^{\circ}$, average drawing is 1.31 according to Table 1. We determine a number of drawings $\ln (4) / \ln (1.31)=5.13$ and round to 5 .

As the drawing sequence is designed according to a linear decreasing graph, we should determine reduction by passes. This sequence has 5 drawings; reduction in the first pass is $28 \%$, and in the third pass is $23.5 \%$, as it follows from Table 1. Then we plot the graph (Figure 3 ) by two points and determine reduction values for dies 2, 4 and 5.

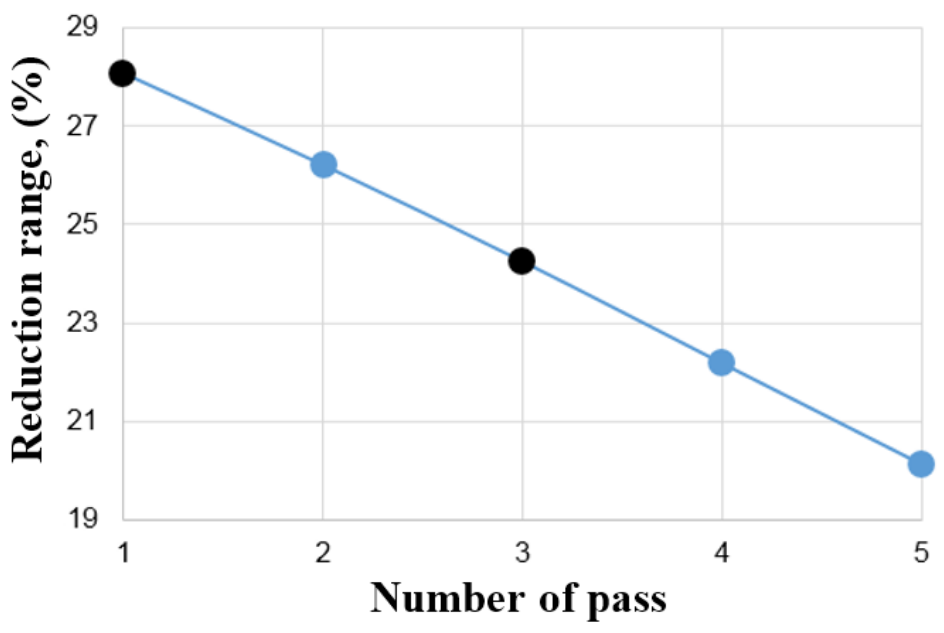

Figure 3 Graph used to determine drawings 2, 4, 5

Thus, we got the following drawing sequence: 16.00-13.57-11.66-10.15-8.95-8.00 mm.

To analyze the suggested sequence with die semi-angles of $6^{\circ}$, we built a graph of changes in hydrostatic stress according to passes (Figure 4). 


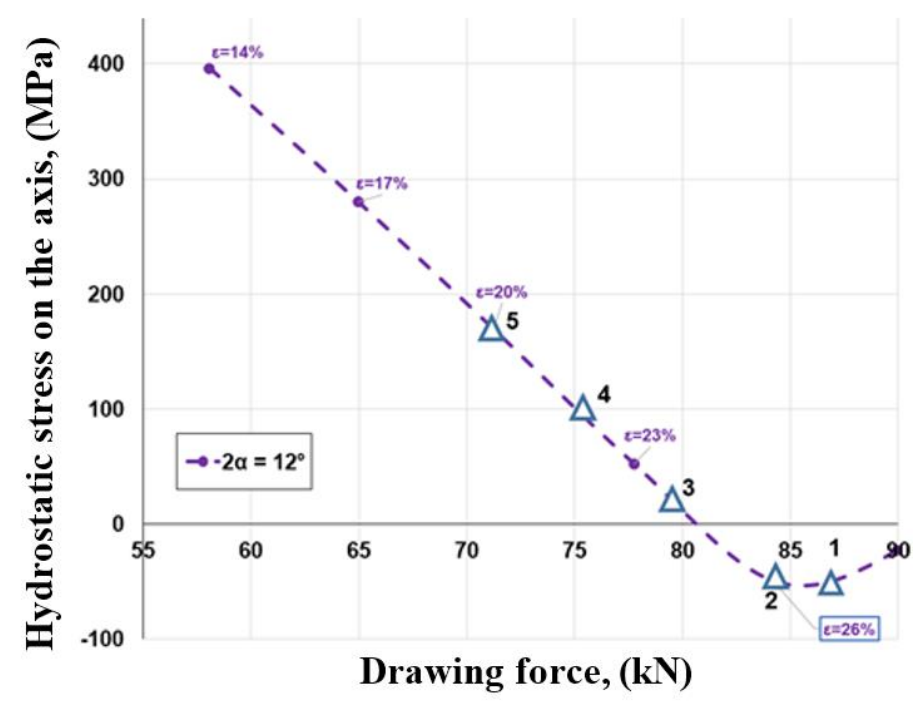

Figure 4 Graph used to determine hydrostatic stress of the suggested sequence

As Figure 4 shows, in the suggested sequence hydrostatic stress values in the first two drawings are negative, while in drawings 3 and 4 it does not exceed $100 \mathrm{MPa}$. Thus, such sequence ensures the most favorable stress state of wire, resulting in its higher quality.

\section{CONCLUSION}

We developed a new procedure and algorithm of calculating drawing sequences, ensuring production of wire with a set level of quality at minimum power and material consumption. This procedure may be applied both for designing new drawing sequences and analyzing existing ones.

\section{ACKNOWLEDGEMENTS}

The study was carried out within the framework of the implementation of the Resolution of the Government of the Russian Federation of April 9, 2010 No. 220 (Contract No. 075-15-2019-869 from May 12, 2019); supported by a grant of the Russian Science Foundation (project No. 20-69-46042 of 20.05.2020); funded by RFBR, project number 20-38-90097.

\section{REFERENCES}

[1] CAO, T.S. Models for ductile damage and fracture prediction in cold bulk metal forming processes. International Journal of Material Forming. [online]. 2017, vol. 10, pp. 139-171. Available from: https://doi.org/10.1007/s12289015-1262-7.

[2] SZYMULA, M., MUSZKA, K., MAJTA, J., PAĆKO, M., DYBICH, J. Study of the effect of Accumulative Angular Drawing deformation route on grain refinement in 304L stainless steel. Procedia Manufacturing. [online]. 2020, vol. 50, pp. 350-354. Available from: https://doi.org/10.1016/j.promfg.2020.08.065.

[3] MAJTA, J., PERZYŃSKI, K., MUSZKA, K., GRACA, P., MADEJ, L. Modeling of grain refinement and mechanical response of microalloyed steel wires severely deformed by combined forming proces. The International Journal of Advanced Manufacturing Technology. [online]. 2017, vol. 89, pp. 1559-1574. Available from: https://doi.org/10.1007/s00170-016-9203-2.

[4] SAS-BOCA, I.M., TINTELECAN, M., POP, M., ILUTुIU-VARVARA, D.-A., MIHU, A.M. The wire drawing process simulation and the optimization of geometry dies. Procedia Engineering. [online]. 2017, vol. 181, pp. 187-192. Available from: https://doi.org/10.1016/j.proeng.2017.02.368.

[5] KHARITONOV, V.A., USANOV, M.YU. Evaluation of efficiency of methods for drawing round wire with large diameters. Chernye Metally. [online]. 2021, no. 3, pp. 28-33. Available from:

https://doi.org/10.17580/chm.2021.03.05. 